\title{
Analysis of Mining Subsidence in Yushenfu Mining Area Based on Key Strata Theory
}

\author{
Yanjie Sun ${ }^{1, a}$, Shijie Song ${ }^{1, b}$, Xiaoguang Zhao ${ }^{1}$ and Wenjie Nie ${ }^{1}$ \\ ${ }^{1} \mathrm{Xi}$ ' an University of Science and Technology, Xi' an ,China \\ a747720426@qq.com, b470634101@qq.com
}

\begin{abstract}
Keywords: mining subsidence;sandstone layer number; ratio of rock to soil; mining depth.
Abstract. Taking Yushenfu mining coal area in northern Shaanxi as the research area, the geological structure of the whole coal-bearing strata was selected as the research object. In this paper, 80 structural models of overburden strata were constructed according to the main geological structure of the mining area. The ratio of rock to soil, coal mining depth and sandstone layer number were taken as the three factors influencing the stability of overburden strata. Based on the key strata theory, three influencing factors were analyzed by mechanical method and multiple regression analysis in order to find the most influential factors of overburden stability.
\end{abstract}

\section{Introduction}

After the underground mining, the original stress equilibrium state of the strata is broken, which will cause the overlying strata to move in the mined-out area. When the mining area reaches a certain extent, the strata movement will spread to the surface and cause the surface subsidence [1]. According to the survey, Shenhua Shendong company formed a total area of $43.33 \mathrm{~km}^{2}$ subsidence, accounting for $93.3 \%$ of the county subsidence area, the formation of mining coal mining area of $0.2 \mathrm{~km}^{2}$ per million tons of coal. Thus, mining mining subsidence caused by the problem has been serious to shocking point [2]. To this end, our scholars on the mining subsidence carried out a lot of research [3-6].

\section{Methods and Principles}

The key strata theory, founded by Qian[7], has revealed the intrinsic connection of overburden failure in coal mining, which not only makes an important contribution to the strata pressure theory, but also has been extensively used in mining subsidence application. Therefore, based on the theory of "key strata theory", the stress and deformation of rock strata in elastic or approximate elastic conditions during mining are regarded as two-end consolidation beam structure.

According to the structural mechanics of beams, the following equation[8] can be written:Below is the maximum bending moment (pull-down) equation for the beam and the maximum tensile stress equation. Equation 1 is the maximum bending moment equation, and equation 2 is the maximum tensile stress equation.

$$
Q_{\text {pull max }}=\frac{6 X}{b h^{2}}
$$

In the equation $h$ is the bedrock sand thickness [m], $b$ is the beam cross-sectional width [m] .

$$
\mathrm{f}=\frac{q l^{4}}{384 E I}
$$

In the equation, $q$ is the load $[\mathrm{KN} \cdot \mathrm{m}]$ and $l$ is the $\operatorname{span}[\mathrm{m}] . E$ is the elastic modulus and $I$ is the moment of inertia.

\section{Calculation and Analysis}

According to the geological characteristics of Yushenfu mining area, 40 structural models are constructed. The ratio of rock to soil for the class A (or a) is $3: 1$, the code of B (or b) is 4: 1, the code 
of $\mathrm{C}$ (or c) is 7: 1,the code of $\mathrm{D}$ (or d) is 7: 1. As the depth of coal mining is different, this paper divides 40 models into structural model with mining depth of $250 \mathrm{~m}$ and structural model with mining depth of $300 \mathrm{~m}$. All models are $5 \mathrm{~m}$ high, and do not consider the inclination.

Construction of Structural Model. According to different coal mining depth, this paper divides the model structure into the model structure with coal mining depth of $250 \mathrm{~m}$ and model structure with coal mining depth of $300 \mathrm{~m}$.

Structural Model of Mining Depth of 250m. Coal layer overlying strata for the whole section of fine powder layer structure, coal mining depth of $250 \mathrm{~m}$. The model will be divided into A,B,C,D four parts according to different ratio of rock to soil in overburden rock, the concrete situation is shown in Table 1.

Table 1 Structural Model of Coal Mining Depth of 250m

\begin{tabular}{|c|c|c|c|c|c|}
\hline \multirow{2}{*}{ Ratio of rock to soil } & \multirow{2}{*}{ Types } & \multirow{2}{*}{$\begin{array}{l}\text { Loess (layers / } \\
\text { thickness)[m] }\end{array}$} & \multirow{2}{*}{$\begin{array}{l}\text { Red soil (layer / } \\
\text { thickness)[m] }\end{array}$} & \multicolumn{2}{|c|}{ Fine sandstone interbeds (layers / thickness) } \\
\hline & & & & Fine sandstone $[\mathrm{m}]$ & Siltstone $[\mathrm{m}]$ \\
\hline \multirow{5}{*}{$3: 1$} & A1 & $1 / 25$ & $1 / 37.5$ & $5 / 18.75$ & $5 / 18.75$ \\
\hline & A2 & $1 / 25$ & $1 / 37.5$ & $6 / 15.625$ & $6 / 15.625$ \\
\hline & A3 & $1 / 25$ & $1 / 37.5$ & $10 / 9.375$ & $10 / 9.375$ \\
\hline & A4 & $1 / 25$ & $1 / 37.5$ & $15 / 6.25 \mathrm{~m}$ & $15 / 6.25$ \\
\hline & A5 & $1 / 25$ & $1 / 37.5$ & $20 / 4.6875$ & $20 / 4.6875$ \\
\hline \multirow{5}{*}{$4: 1$} & B1 & $1 / 20$ & $1 / 30$ & $5 / 20$ & $5 / 20$ \\
\hline & B2 & $1 / 20$ & $1 / 30$ & $6 / 16.68$ & $6 / 16.68$ \\
\hline & B3 & $1 / 20$ & $1 / 30$ & $10 / 10 \mathrm{~m}$ & $10 / 10$ \\
\hline & B4 & $1 / 20$ & $1 / 30$ & $1 / 6.76,14 / 6.66$ & $1 / 6.76,14 / 6.66$ \\
\hline & B5 & $1 / 20$ & $1 / 30$ & $20 / 5$ & $20 / 5$ \\
\hline \multirow{5}{*}{$7: 1$} & $\mathrm{C} 1$ & $1 / 12.5$ & $1 / 18.75$ & $5 / 21.875$ & $5 / 21.875$ \\
\hline & $\mathrm{C} 2$ & $1 / 12.5$ & $1 / 18.75$ & $1 / 18.23,5 / 18.229$ & $1 / 18.23,5 / 18.229$ \\
\hline & $\mathrm{C} 3$ & $1 / 12.5$ & $1 / 18.75$ & $10 / 10.9375$ & $10 / 10.9375$ \\
\hline & $\mathrm{C} 4$ & $1 / 12.5$ & $1 / 18.75$ & $3 / 7.3,12 / 7.29$ & $2 / 7.3,13 / 7.29$ \\
\hline & $\mathrm{C} 5$ & $1 / 12.5$ & $1 / 18.75$ & $20 / 5.46875$ & $20 / 5.46875$ \\
\hline \multirow{5}{*}{$9: 1$} & D1 & $1 / 10$ & $1 / 15$ & $5 / 22.5$ & $5 / 22.5$ \\
\hline & D2 & $1 / 10$ & $1 / 15$ & $6 / 18.75$ & $6 / 18.75$ \\
\hline & D3 & $1 / 10$ & $1 / 15$ & $10 / 11.25$ & $10 / 11.25$ \\
\hline & D4 & $1 / 10$ & $1 / 15$ & $15 / 7.5$ & $15 / 7.5$ \\
\hline & D5 & $1 / 10$ & $1 / 15$ & $20 / 5.625$ & $20 / 5.625$ \\
\hline
\end{tabular}

Structural Model of Mining Depth of 300m. Coal layer overlying strata for the whole section of fine powder layer structure, mining depth of $300 \mathrm{~m}$. Structural model The model will be divided into four parts $(\mathrm{a}, \mathrm{b}, \mathrm{c}, \mathrm{d})$ according to the different ratio of rock to soil in overburden rock, the concrete situation is shown in Table 2 .

Table 2 Structural Model of Coal Mining Depth of 300m

\begin{tabular}{|c|c|c|c|c|c|}
\hline \multirow{2}{*}{ Ratio of rock to soil } & \multirow{2}{*}{ Types } & \multirow{2}{*}{$\begin{array}{l}\text { Loess (layers / } \\
\text { thickness)[m] }\end{array}$} & \multirow{2}{*}{$\begin{array}{l}\text { Red soil (layer / } \\
\text { thickness) [m] }\end{array}$} & \multicolumn{2}{|c|}{ Fine sandstone interbeds (layers / thickness) } \\
\hline & & & & Fine sandstone $[\mathrm{m}]$ & Siltstone[m] \\
\hline \multirow{4}{*}{$3: 1$} & a1 & $1 / 30$ & $1 / 45$ & $5 / 22.5$ & $5 / 22.5$ \\
\hline & a2 & $1 / 30$ & $1 / 45$ & $6 / 18.75$ & $6 / 18.75$ \\
\hline & a3 & $1 / 30$ & $1 / 45$ & $10 / 11.25$ & $10 / 11.25$ \\
\hline & a4 & $1 / 30$ & $1 / 45$ & $15 / 7.5$ & $15 / 7.5$ \\
\hline \multirow{7}{*}{$4: 1$} & a5 & $1 / 30$ & $1 / 45$ & $20 / 5.625$ & $20 / 5.625$ \\
\hline & b1 & $1 / 24$ & $1 / 36$ & $5 / 24$ & $5 / 24$ \\
\hline & b2 & $1 / 24$ & $1 / 36$ & $6 / 20$ & $6 / 20$ \\
\hline & b3 & $1 / 24$ & $1 / 36$ & $10 / 12$ & $10 / 12$ \\
\hline & b4 & $1 / 24$ & $1 / 36$ & $15 / 8$ & $15 / 8$ \\
\hline & b5 & $1 / 24$ & $1 / 36$ & $20 / 6$ & $20 / 6$ \\
\hline & $\mathrm{c} 1$ & $1 / 15$ & $1 / 22.5$ & $5 / 26.25$ & $5 / 26.25$ \\
\hline \multirow{4}{*}{$7: 1$} & c2 & $1 / 15$ & $1 / 22.5$ & $6 / 21.875$ & $6 / 21.875$ \\
\hline & c3 & $1 / 15$ & $1 / 22.5$ & $10 / 13.125$ & $10 / 13.125$ \\
\hline & c4 & $1 / 15$ & $1 / 22.5$ & $15 / 8.75$ & $15 / 8.75$ \\
\hline & $\mathrm{c} 5$ & $1 / 15$ & $1 / 22.5$ & $20 / 6.5625$ & $20 / 6.5625$ \\
\hline \multirow{5}{*}{$9: 1$} & $\mathrm{~d} 1$ & $1 / 12$ & $1 / 18$ & $5 / 27$ & $5 / 27$ \\
\hline & $\mathrm{d} 2$ & $1 / 12$ & $1 / 18$ & $6 / 22.5$ & $6 / 22.5$ \\
\hline & $\mathrm{d} 3$ & $1 / 12$ & $1 / 18$ & $10 / 13.5$ & $10 / 13.5$ \\
\hline & $\mathrm{d} 4$ & $1 / 12$ & $1 / 18$ & $15 / 9$ & $15 / 9$ \\
\hline & d5 & $1 / 12$ & $1 / 18$ & $20 / 6.75$ & $20 / 6.75$ \\
\hline
\end{tabular}

Calculation of Mechanical Parameters of Model. According to the force of the beam, we generally only in the mining process of the rock layer by the maximum tensile stress and the maximum deflection produced. 
The Mechanical Parameters of Structural Model with Mining Depth of $250 \mathrm{~m}$. According to Equations 1 and 2, we can see the mechanical parameters of the structural model with the depth of $250 \mathrm{~m}$. The results are shown in Table 3.

Table 3 Mechanical parameters of structural model with mining depth of $250 \mathrm{~m}$

\begin{tabular}{|c|c|c|c|c|c|c|}
\hline \multirow{2}{*}{ Model } & \multicolumn{3}{|c|}{ Load[kN/m] } & \multirow{2}{*}{$\mathrm{E}[\mathrm{MPa}]$} & \multirow{2}{*}{ Maximum tensile stress $\left[\mathrm{kN} / \mathrm{m}^{2]}\right.$} & \multirow{2}{*}{ Maximum deflection $\left[10^{-10} \mathrm{~m}\right]$} \\
\hline & $Q_{\text {loess }}$ & $Q_{\text {Red soil }}$ & QSandstone & & & \\
\hline A1 & 430 & 697.5 & 4556.25 & 7240 & $0.20 * \mathrm{l}^{2}$ & $0.93 * 1^{4}$ \\
\hline A2 & 430 & 697.5 & 4556.25 & 7240 & $0.24 * 1^{2}$ & $1.34 * 1^{4}$ \\
\hline A3 & 430 & 697.5 & 4556.25 & 7240 & $0.40 * 1^{2}$ & $3.72 * 1^{4}$ \\
\hline A4 & 430 & 697.5 & 4556.25 & 7240 & $0.61 * 1^{2}$ & $8.37 * 1^{4}$ \\
\hline A5 & 430 & 697.5 & 4556.25 & 7240 & $0.81 * 1^{2}$ & $14.9 * 1^{4}$ \\
\hline B1 & 344 & 558 & 4860 & 7240 & $0.18 * 1^{2}$ & $0.78 * 1^{4}$ \\
\hline B2 & 344 & 558 & 4860 & 7240 & $0.22 * 1^{2}$ & $1.12 * 1^{4}$ \\
\hline B3 & 344 & 558 & 4860 & 7240 & $0.36 * 1^{2}$ & $3.11 * 1^{4}$ \\
\hline B4 & 344 & 558 & 4860 & 7240 & $0.54 * 1^{2}$ & $7.02 * 1^{4}$ \\
\hline B5 & 344 & 558 & 4860 & 7240 & $0.72 * 1^{2}$ & $12.4 * 1^{4}$ \\
\hline $\mathrm{C} 1$ & 215 & 348.75 & 5315.6 & 7240 & $0.15 * 1^{2}$ & $0.61 * 1^{4}$ \\
\hline $\mathrm{C} 2$ & 215 & 348.75 & 5315.6 & 7240 & $0.18 * 1^{2}$ & $0.87 * 1^{4}$ \\
\hline $\mathrm{C} 3$ & 215 & 348.75 & 5315.6 & 7240 & $0.31 * 1^{2}$ & $2.42 * 1^{4}$ \\
\hline $\mathrm{C} 4$ & 215 & 348.75 & 5315.6 & 7240 & $0.46 * 1^{2}$ & $5.44 * 1^{4}$ \\
\hline $\mathrm{C} 5$ & 215 & 348.75 & 5315.6 & 7240 & $0.61 * 1^{2}$ & $9.69 * 1^{4}$ \\
\hline D1 & 172 & 279 & 5467.5 & 7240 & $0.15 * 1^{2}$ & $0.56 * 1^{4}$ \\
\hline D2 & 172 & 279 & 5467.5 & 7240 & $0.18 * 1^{2}$ & $0.81 * 1^{4}$ \\
\hline D3 & 172 & 279 & 5467.5 & 7240 & $0.29 * 1^{2}$ & $2.24 * 1^{4}$ \\
\hline D4 & 172 & 279 & 5467.5 & 7240 & $0.44 * 1^{2}$ & $5.05 * 1^{4}$ \\
\hline D5 & 172 & 279 & 5467.5 & 7240 & $0.58 * 1^{2}$ & $8.97 * 1^{4}$ \\
\hline
\end{tabular}

The Mechanical Parameters of Structural Model with Mining Depth of 300m. According to Equations 1 and 2, we can see the mechanical parameters of the structural model with the depth of $250 \mathrm{~m}$. The results are shown in Table 4.

Table 4 Mechanical parameters of structural model with mining depth of $300 \mathrm{~m}$

\begin{tabular}{|c|c|c|c|c|c|c|}
\hline \multirow{2}{*}{ Model } & \multicolumn{3}{|c|}{$\operatorname{Load}[\mathrm{kN} / \mathrm{m}]$} & \multirow{2}{*}{$\mathrm{E}[\mathrm{MPa}]$} & \multirow{2}{*}{ Maximum tensile stress $\left[\mathrm{kN} / \mathrm{m}^{2]}\right.$} & \multirow{2}{*}{ Maximum deflection $\left[10^{-10} \mathrm{~m}\right]$} \\
\hline & $Q_{\text {loess }}$ & $\mathrm{Q}_{\text {Red soil }}$ & QSandstone & & & \\
\hline a1 & 516 & 837 & 5467.5 & 7240 & $0.17 * 1^{2}$ & $0.65 * 1^{4}$ \\
\hline a2 & 516 & 837 & 5467.5 & 7240 & $0.20 * 1^{2}$ & $0.93 * 1^{4}$ \\
\hline a3 & 516 & 837 & 5467.5 & 7240 & $0.34 * 1^{2}$ & $2.58 * 1^{4}$ \\
\hline $\mathrm{a} 4$ & 516 & 837 & 5467.5 & 7240 & $0.51 * 1^{2}$ & $5.82 * 1^{4}$ \\
\hline a5 & 516 & 837 & 5467.5 & 7240 & $0.67 * 1^{2}$ & $10.3 * 1^{4}$ \\
\hline b1 & 412.8 & 669.6 & 5832 & 7240 & $0.15 * 1^{2}$ & $0.54 * 1^{4}$ \\
\hline $\mathrm{b} 2$ & 412.8 & 669.6 & 5832 & 7240 & $0.18 * 1^{2}$ & $0.78 * 1^{4}$ \\
\hline b3 & 412.8 & 669.6 & 5832 & 7240 & $0.30 * 1^{2}$ & $2.16 * 1^{4}$ \\
\hline b4 & 412.8 & 669.6 & 5832 & 7240 & $0.45 * 1^{2}$ & $4.86 * 1^{4}$ \\
\hline b5 & 412.8 & 669.6 & 5832 & 7240 & $0.60 * 1^{2}$ & $8.64 * 1^{4}$ \\
\hline $\mathrm{c} 1$ & 258 & 418.5 & 6378.75 & 7240 & $0.13 * 1^{2}$ & $0.42 * 1^{4}$ \\
\hline $\mathrm{c} 2$ & 258 & 418.5 & 6378.75 & 7240 & $0.15 * 1^{2}$ & $0.61 * 1^{4}$ \\
\hline c3 & 258 & 418.5 & 6378.75 & 7240 & $0.26 * 1^{2}$ & $1.68 * 1^{4}$ \\
\hline $\mathrm{c} 4$ & 258 & 418.5 & 6378.75 & 7240 & $0.38 * 1^{2}$ & $3.79 * 1^{4}$ \\
\hline$c 5$ & 258 & 418.5 & 6378.75 & 7240 & $0.51 * 1^{2}$ & $6.73 * 1^{4}$ \\
\hline $\mathrm{d} 1$ & 206.4 & 334.8 & 6561 & 7240 & $0.12 * 1^{2}$ & $0.39 * 1^{4}$ \\
\hline $\mathrm{d} 2$ & 206.4 & 334.8 & 6561 & 7240 & $0.15 * 1^{2}$ & $0.56 * 1^{4}$ \\
\hline $\mathrm{d} 3$ & 206.4 & 334.8 & 6561 & 7240 & $0.24 * 1^{2}$ & $1.56 * 1^{4}$ \\
\hline $\mathrm{d} 4$ & 206.4 & 334.8 & 6561 & 7240 & $0.37 * 1^{2}$ & $3.50 * 1^{4}$ \\
\hline d5 & 206.4 & 334.8 & 6561 & 7240 & $0.49 * 1^{2}$ & $6.23 * 1^{4}$ \\
\hline
\end{tabular}

Mechanical Analysis.In order to more clearly analyze the mechanical properties of the model, here the use of EXCLE model of the mechanical parameters of the trend of image. In order to facilitate the mapping of all the curves in this paper are not expressed in the span $l$. The specific situation shown in Fig. 1 and Fig. 2.

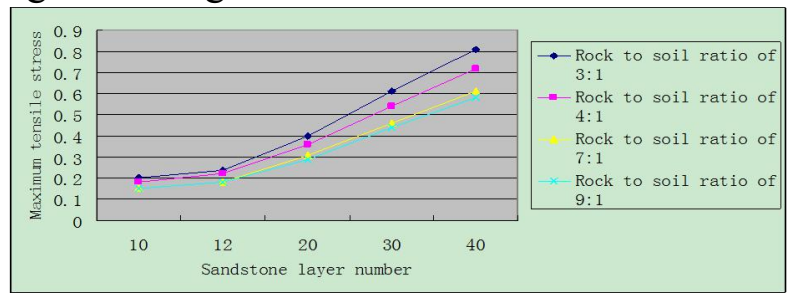

(a)

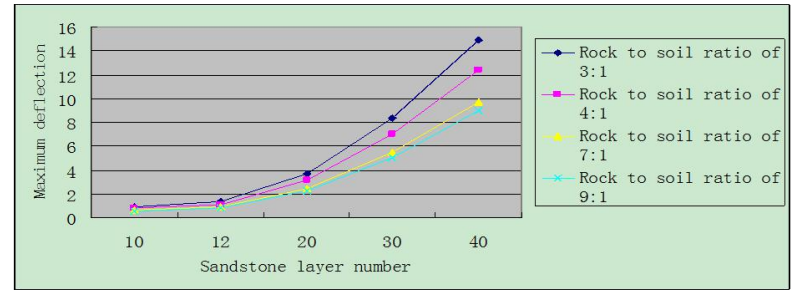

(b)

Fig.1 Mechanical trend of overlying strata with mining depth of $250 \mathrm{~m}$ : a. Maximum tensile stress change trend; $b$. The maximum deflection trend. 


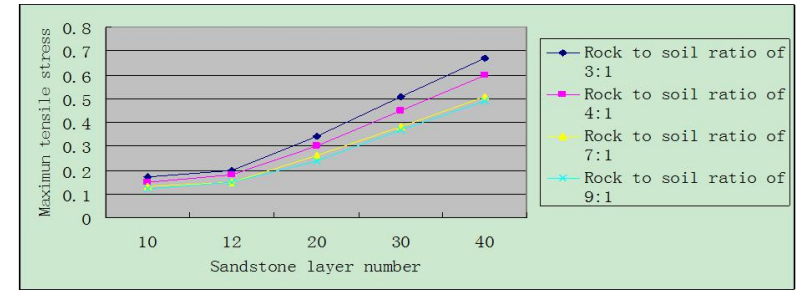

(c)

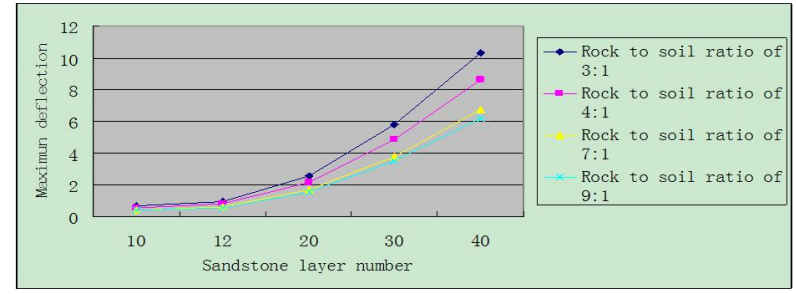

(d)

Fig.2 Mechanical trend of overlying strata with 300m depth of coal mining: c. Tendency of maximum tensile stress; $d$. Trend of maximum deflection.

Influence of Sandstone Layer Number on Model Mechanics.From Fig. 2 and Fig. 3, it is obvious that the maximum tensile stress and the maximum deflection produced increase with the increase of the number of sandstone layers.

From the mechanical formula can be seen, the size of the tensile stress and rock thickness was inversely proportional relationship. The thinner the rock strata, the greater the tensile stress will be. In the case of constant coal thickness, the increase in the number of strata must result in a reduction in the thickness of each formation. Therefore, with the increase of sandstone strata, the maximum tensile stress of the whole structure will be increased, and the influence of the whole rock mass will also increase gradually. At the same time, with the increase of the sandstone layer, the maximum deflection of the whole structure will increase. It can be obtained that the tensile stress and deflection of the rock mass will increase with the increase of the strata number of rock strata under the same condition, and the whole stability of the rock mass will be weakened and more likely to occur Subsidence.

Influence of Geotechnical Comparison on Model Mechanics.From Fig. 2 and Fig. 3, it can be found that the maximum tensile stress and maximum deflection produced by the corresponding rock strata structure are smaller when the ratio of sand and rock is constant.

The tensile stress is inversely proportional to the thickness of rock strata. The thinner the strata are, the larger the tensile stress is. The increase of rock-soil ratio will increase the thickness of rock strata under the condition of constant depth and the number of strata. According to Eq. (1), it can be found that the maximum tensile stress of the whole rock mass increases with the increase of rock-soil ratio under the condition of bed thickness, sand layer number and rock mass structure invariable. The impact of the entire rock will be gradually increased. The moment of inertia is directly proportional to the thickness of the rock, so the moment of inertia is inversely proportional to the maximum deflection. According to equation (2), the greater the thickness of the layer, the smaller the deflection of the rock is, because the thickness of strata and the strata of strata are not Change, the greater the ratio of rock and soil to prove that the thicker rock, and therefore the deflection of the rock will be smaller.

Multivariate Regression Analysis of Results. Because the thickness of coal mining in Fig. 2 and Fig. 3 has little effect on the mechanical structure of the model, a multivariate regression analysis will be used to analyze the various factors of the mechanical properties of the model. In order to facilitate the calculation here, the coal depth is set to $\mathrm{x} 1$, the number of sandstone layers is set to $\mathrm{x} 2$ and the ratio of rock and soil is set to $\mathrm{x} 3$. The fitting of each factor to the maximum tensile stress and the resulting maximum deflection of the overburden structure is shown in Table 5.

Table 5 Different factors and rock mass maximum tensile stress and deflection of the fit

\begin{tabular}{ccccc}
\hline Influencing factors & P-value & The fitted equation (with maximum tensile stress) & Correlation coefficient & Significance F \\
\hline Mining depth & $4.79 \mathrm{E}-07$ & & & \\
Sandstone layer number & $6.36 \mathrm{E}-28$ & $\mathrm{y}=0.471021-0.0013 \times 1+0.015499 \times 2-0.0189 \times 3$ & $\mathrm{R}^{2}=0.972181$ & $2.84 * 10^{-27}$ \\
Ratio of rock to soil & $5.28 \mathrm{E}-10$ & & & Sorrelation coefficient \\
\hline Influencing factors & P-value & The fitted equation (with maximum deflection) & Signicance $\mathrm{F}$ \\
\hline Mining depth & 0.000697 & & \multirow{2}{*}{$\mathrm{R}^{2}=0.907801$} & $3.52^{*} 10^{-18}$ \\
Sandstone layer number & $6.9 \mathrm{E}-19$ & $\mathrm{y}=6.859882-0.02845 \times 1+0.297762 \times 2-0.32339 \times 3$ & & \\
Ratio of rock to soil & 0.000298 & & & \\
\hline
\end{tabular}

As can be seen from Table 5, the three factors of the P values are less than 0.05 , indicating that the three independent variables with the maximum deflection and maximum tensile stress; the maximum 
deflection and maximum tensile stress in the table correlation coefficient greater than 0.9, indicating different Factor is closely related to the mechanical properties of overlying strata; Significance $\mathrm{F}$ is close to 0 , the regression equation is very significant. It can be concluded that the maximum influencing factors of rock mechanical properties are the sandstone strata, the second is the ratio of rock to rock and soil, the least influencing factor is the coal mining depth, the depth of coal mining, the ratio of rock and soil and the maximum tensile stress And the resulting maximum deflection is inversely proportional.

\section{Conclusions}

Through the analysis of the results, we can get the following conclusions:

(1)In the whole section of fine-grained interbedded structure, the sandstone layer number,mining depth and ratio of rock to soil for coal-bearing strata will influence the stability of overburden;

(2)The increase in the number of sand layers will make the maximum tensile stress and the maximum deflection of overburden were increased, but the increase on ratio of rock to soil and coal-mining depth will make the maximum tensile stress and maximum deflection of the coal-bearing strata become smaller.

(3)In the interbedded structure, the sandstone layer number of coal strata is the greatest influence on the stability in the overlying strata, and the coal mining depth is the least effect on the stability of the overlying strata.

\section{Acknowledgements}

This work was financially supported by the National Science Foundation for Young Scientists of China (NO.41402308), Scientific Research Program Funded by Shaanxi Provincial Education Department (NO.14JK1466).

\section{References}

[1] J.B. Wang, X.R. Liu and X.J. Liu: Journal of China Coal Society. Vol. 40 (2015), p.516-521

[2] S.J. Song, X.G. Zhao and R. Liu et al: Coal Mine Safety.Vol. (2010),p.138-140,146

[3] S.J. Song, X.G. Zhao and S.M. Wang et al: Mining Safety \& Environmental Protection.Vol. 41(2014),p.9-12,16

[4] S.J. Song, X.G. Zhao and S.M. Wang: Coal Mine Safety.Vol. 45(2014),p. 60-63

[5] S.J. Song: The Quantitative Evaluation of Eco-Environment Damage Induced by Coal Exploitation in Yushenfu Mining Area(2009)

[6] S.J. Song, X.G. Zhao and S.M. Wang et al: Coal Mine Safety.Vol.21(1996),p.225-230

[7] M.G. Qian, X.X. Liao and J.L. Xu:Journal of China Coal Society.Vol.40 (2015), p.516-521

[8] S.J. Song:Study on the Stratification Transfer Prediction Method of the Mining Subsidence Based on the Key Geological and Mining(2013) 